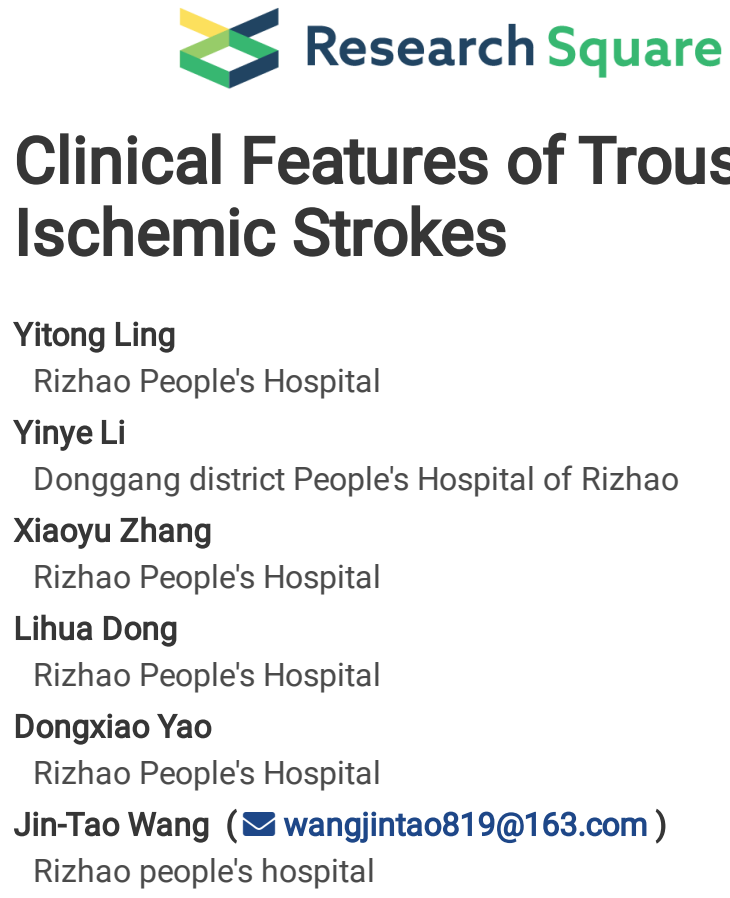

\title{
Clinical Features of Trousseau's Syndrome with Multiple Acute Ischemic Strokes
}

Research article

Keywords: Trousseau's syndrome, multiple acute ischemic strokes, cancer, NIHSS, D-dimer level, magnetic resonance image

Posted Date: September 17th, 2020

DOI: https://doi.org/10.21203/rs.3.rs-50061/v1

License: ( ) (1) This work is licensed under a Creative Commons Attribution 4.0 International License. Read Full License

Version of Record: A version of this preprint was published at Neurological Sciences on September 26th, 2021. See the published version at https://doi.org/10.1007/s10072-021-05619-y. 


\section{Abstract}

\section{Background:}

Trousseau's syndrome can cause venous or arterial thrombosis, multiple acute ischemic strokes (MAIS) caused by Trousseau's syndrome is rare. The aim of this study was to analyze the clinical features of Trousseau's syndrome with MAIS, and to improve the awareness and the knowledge of this disease.

\section{Methods:}

Clinical data from fifteen patients who were diagnosed as Trousseau's Syndrome with MAIS in Rizhao people's Hospital from January 2017 to April 2020 were collected and analyzed. The clinical data included the following: Patients' basic information, laboratory results, imaging features, treatment regimens, and short-term prognoses were collected.

\section{Results:}

The mean age was 65.5 years, with thirteen males and two females. Most patients (11/15) had a history of smoking and (or) drinking. The average score of NIHSS was 2.13. 6 of the 15 patients first presented with ischemic stroke, and then found the primary tumor. Most common types of primary tumor was lung cancer (11/15), other types of primary tumor were gastric adenocarcinoma, renal cell carcinoma, esophageal adenosquamous carcinoma, and cholangiocarcinoma (one in each). All the 15 patients showed different levels of increase of D-dimer. The increase in CRP appears in 10 of the 15 patients. Various tumor markers were increased in the 15 patients, Especially for CYFRA-211, all the patients of which were higher than normal. All of the 15 patients had multiple vascular territories lesions in DWI, and most lesions were near the cortex areas. Only 4 of the 15 patients $(26.7 \%)$ occurred with Peripheral venous thrombosis. 13 patients were given low molecular heparin for anticoagulant therapy, of which 9 patients were improved in short-term while 4 patients were not.

\section{Conclusion:}

Trousseau's syndrome with MAIS was associated with old-age male, smoking and (or) drinking history, low NIHSS score, increased Ddimer, CRP and tumor markers, lesions near the cortex areas with multiple vascular territories in DWI. Patients with these features should be alert of malignant tumor. Most common types of primary tumor were lung cancer. Treatment with Low molecular heparin may be effective in short-term.

\section{Background}

Trousseau's syndrome was first described in 1865 as the relationship between venous thromboembolisms and cancer [1]. Sack et al. extended this definition to include chronic disseminated intravascular coagulopathy associated with microangiopathy, verrucous endocarpditis, and arterial embolism in patients with cancer [2]. Multiple acute ischemic strokes (MAIS) is a rare manifestation of Trousseau's syndrome, usually involvingelevation of D-dimer levels and acute simultaneous multiple embolisms in multiple vascular territories. There have been few large series studies on Clinical features of Trousseau's syndrome with MAIS. Here, we summarized and analyzed the clinical manifestations, laboratory results and brain magnetic resonance images (MRI) features of fifteen patients who were diagnosed as Trousseau's Syndrome with MAIS in our hospital to improve the awareness and early diagnosis of this disease.

\section{Methods}

Clinical data from fifteen patients who were diagnosed as Trousseau's Syndrome with MAIS in Rizhao people's Hospital from January 2017 to April 2020 were collected and analyzed. The diagnosis of cancer was based on pathological outcome in all the patients. Multiple acute ischemic strokes must have clinical symptoms and be confirmed by MRI diffusion-weighted imaging (DWI). The patients with large vessel disease, small vessel disease, and cardiogenic embolism were excluded. The blood samples and other data were obtained as part of treatment. Clinical data included the following: Patients' necessary information (including gender, age, underlying diseases, and tumor stage), laboratory results (including blood counts, blood coagulation, tumor markers, details of tumor histological type and metastasis), imaging reports (including neck vascular ultrasound, echocardiogram, cranial MRI and MRA), National Institutes of Health Stroke Scale (NIHSS) score, treatment regimens, and short-term prognoses were collected.

\section{Results}


The clinical features of the patients are summarized in Table 1. The mean age was 65.5 years (range 47-75 years), included thirteen females and two males. Six patients first presented with ischemic stroke, and then found the primary tumor. The types of primary tumor were lung cancer in 11 patients (7 patients with adenocarcinoma, 2 patients with squamous carcinoma, and 1 with sarcomatoid carcinoma and 1 with non-small cell carcinoma), and gastric adenocarcinoma, renal cell carcinoma, esophageal adenosquamous carcinoma, and cholangiocarcinoma (one in each) (Fig. 1). Of the 15 patients, 7 had a history of smoking and drinking, 4 had only a history of smoking or drinking, and the remaining 4 had neither a history of smoking nor drinking. There was no history of any condition commonly associated with thrombosis, such as diabetes mellitus, hypertension, hyperlipidemia, coronary heart disease $\llbracket$ rheumatic heart disease and atrial fibrillation. All 15 patients $(100.0 \%)$ had neurological symptoms, including hemiplegia $(n=5)$, dysarthria $(n=3)$, dizziness $(n=3)$, dysphagia $(n=2)$, ataxia $(n=1)$, and disturbance of consciousness $(n=1)$. And the average score of NIHSS was 2.13(range $0-4$ ).In terms of treatment, 13 patients were given low molecular heparin for anticoagulant therapy for 2 weeks, of which 9 patients were improved while 4 patients were not. Two patients were treated with aspirin, one was improved, but another one had poor response and died within a short period of time (one month).

\begin{tabular}{|c|c|c|c|c|c|c|c|c|}
\hline case & Sex & $\begin{array}{l}\text { Previous } \\
\text { history }\end{array}$ & Tumor site & Histological type & Metastasis & Symptom & $\begin{array}{l}\text { NIHSS } \\
\text { (score) }\end{array}$ & Treatment \\
\hline 1 & male & none & lung & adenocarcinoma & none & dizziness & 0 & anticoagulation \\
\hline 2 & male & $\mathrm{BPH}$ & lung & adenocarcinoma & yes & $\begin{array}{l}\text { disturbance of } \\
\text { consciousness }\end{array}$ & 2 & anticoagulation \\
\hline 3 & male & none & lung & adenocarcinoma & yes & hemiplegia & 4 & anticoagulation \\
\hline 4 & male & none & lung & squamous carcinoma & none & hemiplegia & 4 & $\begin{array}{l}\text { anti-platelet } \\
\text { aggregation }\end{array}$ \\
\hline 5 & male & none & lung & $\begin{array}{l}\text { non-small cell } \\
\text { carcinoma }\end{array}$ & none & ataxia & 2 & anticoagulation \\
\hline 6 & male & $\begin{array}{l}\text { bronchial } \\
\text { asthma }\end{array}$ & lung & adenocarcinoma & yes & dysarthria & 2 & anticoagulation \\
\hline 7 & female & none & lung & $\begin{array}{l}\text { sarcomatoid } \\
\text { carcinoma }\end{array}$ & yes & dysphagia & 1 & anticoagulation \\
\hline 8 & male & none & lung & adenocarcinoma & none & hemiplegia & 4 & anticoagulation \\
\hline 9 & male & none & lung & adenocarcinoma & yes & dizziness & 0 & anticoagulation \\
\hline 10 & female & none & lung & adenocarcinoma & none & dysarthria & 2 & anticoagulation \\
\hline 11 & male & none & lung & squamous carcinoma & yes & dysarthria & 2 & anticoagulation \\
\hline 12 & male & none & kidney & renal cell carcinoma & yes & dysphagia & 1 & anticoagulation \\
\hline 13 & male & none & esophageal & squamous carcinoma & none & hemiplegia & 4 & $\begin{array}{l}\text { anti-platelet } \\
\text { aggregation }\end{array}$ \\
\hline 14 & male & $\begin{array}{l}\text { cervical } \\
\text { spondylosis }\end{array}$ & gastric & adenocarcinoma & yes & dizziness & 0 & anticoagulation \\
\hline 15 & male & $\begin{array}{l}\text { gastric } \\
\text { polyps }\end{array}$ & bile ducts & cholangiocawrcinoma & none & hemiplegia & 4 & anticoagulation \\
\hline
\end{tabular}

Analysis of laboratory results

All the 15 patients showed different degrees of increase of D-dimer. The mean D-dimer level was $12.39 \mu \mathrm{g} / \mathrm{ml}$. The increase in CRP appears in 10 of the 15 patients. Various tumor markers were increased in the 15 patients. Especially for CYFRA-211, all the patients of which is higher than normal. Most patients showed an increase in NSE, CA125, CA153, and CA199. In the meantime, we found an increase in CA724 in only two patients, and AFP was normal in all patients. 
Table 2

D-dimer, the normal range is $0-1.5 \mathrm{ug} / \mathrm{ml}$; CRP, C-reactive protein, the normal range is $0-10 \mathrm{mg} / \mathrm{L}$; CYFRA-211, cytokeratin 19 fragment; the normal range is $0-3.3 \mathrm{ng} / \mathrm{ml}$; NSE, neuronspecific enolase; the normal range is 0 $16.3 \mathrm{ng} / \mathrm{ml}$; CEA, carcinoembryonic antigen; the normal range is 0-3.4 ng/ml; AFP, alpha fetoprotein; the normal range is $0-13.6 \mathrm{ng} / \mathrm{ml}$; CA- 125 , carbohydrate antigen-125; the normal range is $0-35 \mathrm{u} / \mathrm{ml}$; CA-153, carbohydrate antigen-153; the normal range is $0-25 \mathrm{u} / \mathrm{ml}$; CA-199, carbohydrate antigen-199; the normal range is $0-27 \mathrm{u} / \mathrm{ml}$; CA-724, carbohydrate antigen-724; the normal range is $0-6.9 \mathrm{u} / \mathrm{ml}$;

\begin{tabular}{|c|c|c|c|c|c|c|c|c|c|c|}
\hline case & $\begin{array}{l}\text { D- } \\
\text { dimer } \\
\text { (ug/ml) }\end{array}$ & $\begin{array}{l}\text { CRP } \\
(\mathrm{mg} / \mathrm{L})\end{array}$ & $\begin{array}{l}\text { CYFRA- } \\
211 \\
\text { (ng/ml) }\end{array}$ & $\begin{array}{l}\text { NSE } \\
\text { (ng/ml) }\end{array}$ & $\begin{array}{l}\text { CEA } \\
\text { (ng/ml) }\end{array}$ & $\begin{array}{l}\text { AFP } \\
(\mathrm{ng} / \mathrm{ml})\end{array}$ & $\begin{array}{l}\text { CA125 } \\
(\mathrm{u} / \mathrm{ml})\end{array}$ & $\begin{array}{l}\text { CA153 } \\
(u / m l)\end{array}$ & $\begin{array}{l}\text { CA199, } \\
(\mathrm{u} / \mathrm{ml})\end{array}$ & $\begin{array}{l}\text { CA724 } \\
(u / m l)\end{array}$ \\
\hline 1 & 24.76 & 20.9 & 15.21 & 22.72 & 52.24 & 2.3 & 1311 & 60.05 & $>1000$ & 2.54 \\
\hline 2 & 14.98 & 210.4 & 37.2 & 29.13 & 6.75 & 2.24 & 1017 & 46.38 & 337.1 & 4.69 \\
\hline 3 & 7.86 & 140.3 & 12.65 & 11.17 & 136.5 & 3.85 & 3341 & 130.2 & $>1000$ & 41.54 \\
\hline 4 & 3.23 & 34.5 & 21.41 & 17.35 & 4.16 & 2.77 & 18.02 & 10.25 & 17.84 & 1.91 \\
\hline 5 & 38.12 & 49.4 & 104.4 & 33.32 & 5.72 & 2.24 & 213.8 & 10.82 & 20.39 & 3.66 \\
\hline 6 & 7.49 & 33.4 & 38.59 & 14.06 & 14.15 & 3.13 & 70.33 & 18.51 & 25.45 & 1.87 \\
\hline 7 & 3.21 & 11 & 74.15 & 38.7 & 1 & 2.50 & 100.56 & 22.35 & 16.32 & 1.93 \\
\hline 8 & 16.34 & 7 & 5.85 & 15.61 & 4.33 & 2.65 & 70.88 & 15.87 & 14.5 & 2.89 \\
\hline 9 & 13.74 & 1.8 & 7.86 & 12.3 & 20.41 & 1.96 & 498.2 & 21.35 & 14.54 & 2.6 \\
\hline 10 & 29.15 & 7.3 & 13 & 16.56 & 6.56 & 2.56 & 82.55 & 9.39 & 13.23 & 2.21 \\
\hline 11 & 1.58 & 3.8 & 7.5 & 11.83 & 1.85 & 6.26 & 18.02 & 8.11 & 30.83 & 3.45 \\
\hline 12 & 3.04 & 53 & 31.8 & 25.72 & 1.84 & 3.71 & 74.3 & 16.2 & 487.2 & 3.23 \\
\hline 13 & 5.68 & 132.3 & 3.84 & 7.89 & 6.58 & 3.29 & 15.07 & 17.53 & 21.85 & 1.19 \\
\hline 14 & 12.05 & 9.4 & 20 & 8.32 & 21.88 & 2.11 & 61.43 & 67.96 & 9.95 & 2.76 \\
\hline 15 & 4.56 & 55 & 23 & 16.68 & 8.12 & 2.32 & 961.9 & 18.32 & 6057 & 45.09 \\
\hline
\end{tabular}

MRI findings

All patients were confirmed with cerebral infarction in brain magnetic resonance imaging (MRI), and all of them had multiple vascular territories lesions in the diffusion-weighted imaging (DWI), most of which were distributed in the bilateral anterior and posterior circulation. Another side, most lesions were near the cortex areas. Cerebral MRA indicated mild atherosclerosis in 5 patients, but no stenosis was observed.

Complementary examinations

There was no evidence of atrial fibrillation on electrocardiography, and echocardiography showed no signs of congenital heart disease or valvular disease. Carotid artery ultrasonography in all patients did not show stenosis. Atherosclerosis was present in 6 patients. 4 of the 15 patients $(26.7 \%)$ included in this study occurred with Peripheral venous thrombosis, including subclavian venous thrombosis $(n=2)$, deep left leg venous thrombosis $(n=2)$, Bilateral calf muscle vein thrombosis $(n=2)$.

\section{Discussion}

The etiology of ischemic stroke is complicated and various. But in clinical work, malignant tumor is often neglected as the cause of ischemic stroke. In the present study, there were 11(73.33\%) cases of lung cancer, including 7 cases of lung adenocarcinoma. It could be seen that Trousseau's syndrome with MAIS was more common in lung cancer, which might be related to the high incidence of lung cancer in Chinese population. In addition, adenocarcinoma had a higher proportion of Trousseau's syndrome with MAIS in lung cancer. This is because the sialic acid moieties of mucin from adenocarcinoma can cause a direct nonenzymatic activation of factor $X$. On the side, carcinoma mucins interact with the selectin adhesion molecule, namely L-selectin, which is expressed on leukocytes, and P-selectin, which is expressed on platelets and endothelial cells. It is more likely to cause ischemic stroke [3]. It is worth noting that in our study, 6 
patients had an ischemic stroke first, and then found a tumor lesion. So, ischemic stroke might be the first manifestation of an undiagnosed cancer [4].

The most common mechanism in patients with Trousseau's syndrome is hypercoagulable state. Its potential mechanisms include hypercoagulability induced by cancer procoagulant, tissue factor, mucin secreted by carcinomas, hypoxia, and the MET oncogene, which upregulates plasminogen activator inhibitor-1 (PAl-1) and cyclooxygenase-2 (COX-2) associated with coagulopathy [5]. In clinical practice, most patients are assessed for hypercoagulability by monitoring their D-dimer levels. Previous studies showed that plasma D-dimer levels were significantly elevated in patients with cancer-associated ischemic stroke compared to those suffering from non-cancer-associated ischemic stroke [6]. Therefore, most scholars believe that Trousseau syndrome is related to increased plasma D-dimer, and if there is no timely diagnosis and treatment, the plasma D-dimer will show persistent increase and recurrent cerebral infarction. Moreover, one research had shown that serial D-dimer levels of 10 patients who died within 90 days were significantly higher than those of the 11 patients who survived up to 90 days [7]. This suggests that serial D-dimer determinations may be a good biomarker and a useful prognostic indicator for Trousseau syndrome patients. In our study, all the 15 patients showed different degrees of increase of D-dimer. The mean D-dimer level was $12.39 \mu \mathrm{g} / \mathrm{ml}$, significantly elevated than normal. So we found D-dimer is an important diagnostic biomarker of Trousseau's syndrome, and confirmed with the previous studies. The other mechanism of Trousseau's syndrome is nonbacterial thrombotic endocarditis (NBTE), which is characterized by nonbacterial vegetation without valvular destruction [8]. But NBTE is diagnosed infrequently before death but prevalence can increase up to $32 \%$ in postmortem series [9]. None of the 15 patients in this study underwent transesophageal echocardiography, so the presence of NBTE could not be completely excluded.

In our study, various tumor markers had increased to varying degrees. Especially for CYFRA-211, all the 15 patients of which is higher than normal. We considered that this might be associated with a higher proportion of lung cancer. Therefore, patients with increased CYFRA-211 in multiple acute ischemic strokes should pay special attention to the possibility of lung cancer. According to previous reports, the serum tumor markers CA19-9 and CA125 were found to be markedly elevated, which may also had been involved in the formation of thromboembolism [10]. Another study had suggested that CA125 and CA15-3 expression were associated with the incidence of thromboembolism in cancer patients, and the significantly increased of CA125 was associated with the recurrence of ischemic strokes in patients with metastatic cancer $[11,12]$. Most patients in our study showed an increase in NSE, CA125, CA153, and CA199. In the meantime, we found AFP was normal in all patients. This is related to the fact that it is a specific indicator of liver cancer. In conclusion, patients with Trousseau's syndrome may have elevated levels of tumor markers, which may also be associated with thromboembolic formation.

We found that the clinical manifestations of patients were hemiplegia, (or) dysarthria and dizziness. The average score of NIHSS was 2.13. So the symptoms and signs of focal neurological deficits in patients with Trousseau's syndrome may be similar with traditional ischemic strokes, but not serious. Four(26.7\%) of our patients had Peripheral venous thrombosis, including subclavian venous thrombosis $(n=2)$, deep left leg venous thrombosis $(n=2)$, Bilateral calf muscle vein thrombosis $(n=2)$. Thus patients with Trousseau's syndrome with MAIS may have vein thrombosis at the same time, which is consistent with other literature reports [13]. This suggests that patients in this category should be alert to the possibility of peripheral venous thrombosis, and perform peripheral vascular examination as soon as possible.

Imaging results in this study revealed that all patients had multiple infarction lesions in DWI, usually with no significant stenosis of the brain arteries on MRA (Fig. 2).Most of the infarct lesions had a characteristic appearance, being nonenhancing, nonring-appearing clusters or single areas of restricted diffusion of $0.5-2 \mathrm{~cm}$ with a peripheral location or larger vascular territories, uncommonly in a watershed distribution, and with absence of diffuse cortical ribbon or deep gray nuclei involvement [14]. In our study, there were 13 patients with bilateral anterior and posterior circulation, 1 patient with unilateral anterior circulation plus posterior circulation, and 1 patient with bilateral anterior circulation. These results suggest that the anterior and posterior circulation is the most compelling MR imaging feature of Trousseau's syndrome with MAIS. In particular, DWI presented a higher proportion of bilateral anterior and bilateral posterior circulation. Some studies sought to highlight the "Three Territory Sign" (TTS) (bilateral anterior and posterior circulation acute ischemic diffusion-weighted imaging [DWI] lesions), as a radiographic marker of stroke due to malignancy $[14,15]$. Therefore, it is necessary to pay attention to the screening of the unknown neoplasia in patients with similar imaging characteristics.

The major approach for treating Trousseau's syndrome is to eliminate the causative tumor [16]. For Trousseau's syndrome with MAIS early anticoagulant therapy is more important. At the present time, direct oral anticoagulants have not been recommended for such patients [5]. Thirteen of the fifteen patients in the present study were given anticoagulation with low molecular heparin, and most of which were improved after treatment and 4 patients were not. So low molecular heparin maybe effectively in a short-term for Trousseau's syndrome with MAIS. 


\section{Conclusions}

The characteristic outcomes of the fifteen patients studied were old-age male, smoking and (or) drinking history, low NIHSS score, increased D-dimer, CRP and tumor markers, lesions near the cortex areas with multiple vascular territories in DWI. Patients with these features should be alert of malignant tumor. Most common types of primary tumors were lung cancer. Treatment with low molecular heparin maybe effectively in short term. This may facilitate to improve the awareness and early diagnosis of this disease.

\section{Abbreviations}

MAIS: Multiple acute ischemic strokes; BPH: Benign Prostatic Hyperplasia; NIHSS: National Institutes of Health Stroke Scale; MRI: Magnetic resonance imaging; DWI: Diffusion-weighted image; MRA: Magnetic resonance angiography;HE: Hematoxylin-eosin; CRP: Creactive protein; CYFRA-211: Cytokeratin 19 fragment; NSE: Neuronspecific enolase; CEA: Carcinoembryonic antigen; AFP: Alpha fetoprotein; CA-125: Carbohydrate antigen-125; CA-153: Carbohydrate antigen-153; CA-199: Carbohydrate antigen-199; CA-724: Carbohydrate antigen-724; PAI-1: Plasminogen activator inhibitor-1; COX-2: cyclooxygenase-2; NBTE: Nonbacterial thrombotic endocarditis; TTS: Three Territory Sign

\section{Declarations}

\section{Acknowledgements}

We thank all patients and their families for generously consenting to use the data in this research.

\section{Author's contribution}

LYT collected and analyzed the clinical data and drafted the manuscript. LYY, ZXY, and YDX participated in the study design and helped to draft the manuscript. DLH and WJT reviewed and edited the manuscript. All authors read and approved the final manuscript.

\section{Funding}

There is no targeted funding for this publication.

\section{Availability of data and materials}

All data generated or analyzed during this study are included in this published article.

\section{Ethics approval and consent to participate}

This study was approved by the ethical committee of Rizhao People's Hospital, and all participants provided informed verbal consent. The consent obtained was verbal because of the infectivity and the exploration urgency for COVID-19. We obtained the verbal consent of the patient or his immediate family members by telephone and the ethics committee approved this procedure. The blood samples and other data were obtained as part of treatment.

\section{Consent for publication}

Not applicable.

\section{Competing interests}

The authors declare that they have no competing interests.

\section{Author details}

${ }^{1}$ Department of Neurology, Rizhao people's hospital, Rizhao 276826, Shandong, China

${ }^{2}$ Department of imaging, Donggang district people's hospital of Rizhao, Rizhao 276826, Shandong, China

${ }^{3}$ Department of emergency, Rizhao people's hospital, Rizhao 276826, Shandong, China

${ }^{4}$ Department of interventional Radiography, Rizhao people's hospital, Rizhao 276826, Shandong, China 


\section{References}

1. T. A, Plegmasia alba dolens, Clinique Medicale de l'Hotel-Dieu Paris, 3 (1865) 654-712.

2. Sack GH Jr, Levin J, Bell WR. Trousseau's syndrome and other manifestations of chronic disseminated coagulopathy in patients with neoplasms: clinical, pathophysiologic, and therapeutic features. Medicine. 1977;56:1-37.

3. Ikushima S, Ono R, Fukuda K, Sakayori M, Awano N, Kondo K. Trousseau's syndrome: cancer-associated thrombosis. Jpn J Clin Oncol. 2016;46:204-8.

4. Chen W, He Y, Su Y. Multifocal cerebral infarction as the first manifestation of occult malignancy: Case series of trousseau's syndrome and literature review. Brain circulation. 2018;4:65-72.

5. Umemura T, Yamamoto J, Akiba D, Nishizawa S. Bilateral cerebral embolism as a characteristic feature of patients with Trousseau syndrome. Journal of clinical neuroscience: official journal of the Neurosurgical Society of Australasia. 2017;42:155-9.

6. Kim SG, Hong JM, Kim HY, Lee J, Chung PW, Park KY, Kim GM, Lee KH, Chung CS, Bang OY, Ischemic stroke in cancer patients with and without conventional mechanisms: a multicenter study in Korea, Stroke, 41 (2010) 798-801.

7. Ito S, Kikuchi K, Ueda A, Nagao R, Maeda T, Murate K, Shima S, Mizutani Y, Niimi Y, Mutoh T. Changes in Serial D-Dimer Levels Predict the Prognoses of Trousseau's Syndrome Patients, Frontiers in neurology, 9 (2018) 528.

8. Takeshita S, Ogata T, Mera H, Tsugawa J, Aoki M, Takeshita M, Tsuboi Y. Multiple Thrombi in the Heart in Trousseau Syndrome Caused by Pancreatic Carcinoma. Journal of stroke cerebrovascular diseases: the official journal of National Stroke Association. 2018;27:e75-7.

9. Taccone FS, Jeangette SM, Blecic SA. First-ever stroke as initial presentation of systemic cancer. Journal of stroke cerebrovascular diseases: the official journal of National Stroke Association. 2008;17:169-74.

10. Kato T, Yasuda K, lida H, Watanabe A, Fujiuchi Y, Miwa S, Imura J, Komiya A. Trousseau's syndrome caused by bladder cancer producing granulocyte colony-stimulating factor and parathyroid hormone-related protein: A case report. Oncology letters.

2016;12:4214-8.

11. Tesselaar ME, Romijn FP, Van Der Linden IK, Prins FA, Bertina RM, Osanto S, Microparticle-associated tissue factor activity: a link between cancer and thrombosis?, Journal of thrombosis and haemostasis: JTH, 5 (2007) 520-527.

12. J. T G, High titers of CA-125 may be associated with recurrent ischemic strokes in patients with cancer, Neurology, 11 (2005) 19441945.

13. Shoko M. Trousseau's Syndrome Causing Refractory Deep Venous Thrombosis, Internal medicine (Tokyo, Japan), 4 (2018) $623-626$.

14. Finelli PF, Nouh A, Three-Territory DWI. Acute Infarcts: Diagnostic Value in Cancer-Associated Hypercoagulation Stroke (Trousseau Syndrome), 37 (2016) 2033-2036.

15. Nouh AM, Staff I, Finelli PF. Three Territory Sign: An MRI marker of malignancy-related ischemic stroke (Trousseau syndrome), Neurology. Clinical practice. 2019;9:124-8.

16. Ishikawa M, Nakayama K, Ishibashi T, Sato E, Nakamura K, Katagiri H, Kyo S. Case series of cerebral infarction with Trousseau's syndrome associated with malignant gynecological tumors. Molecular clinical oncology. 2016;5:138-42.

\section{Figures}



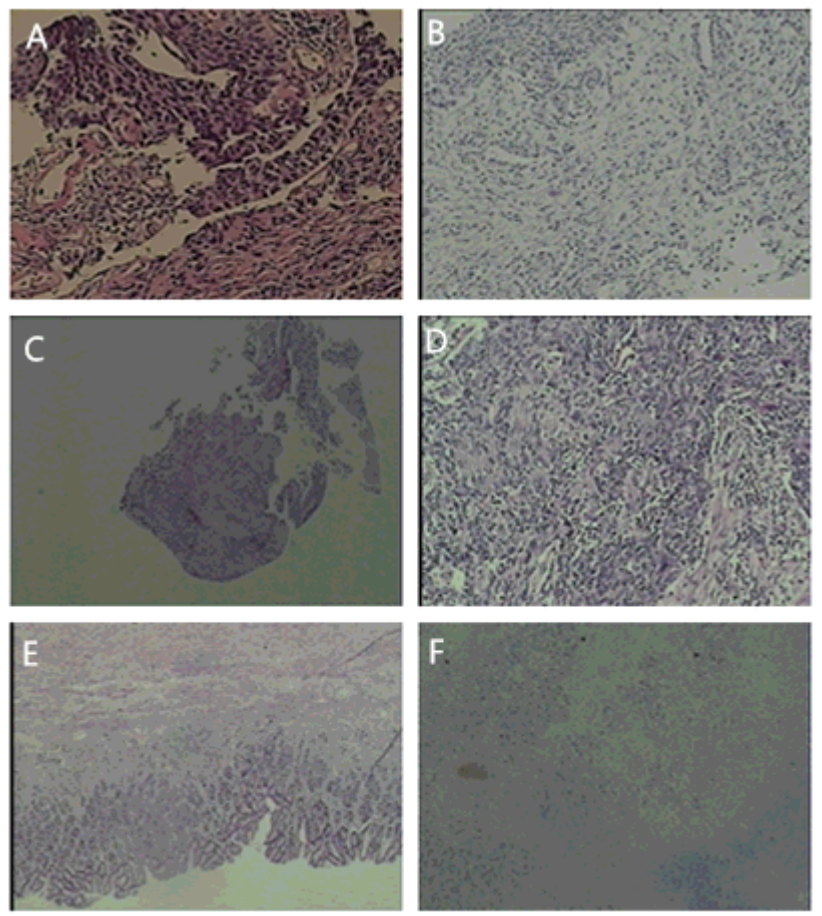

\section{Figure 1}

Histopathological examination of several cases. (A) Histological examination of case 4 demonstrated squamous carcinoma (hematoxylin-eosin [HE]). (B) Immunohistochemical staining results of case 8 revealed the number of positive tumor cells was about $30 \%$, which was consistent with the performance of adenocarcinoma. (C) Case 12 showed poorly differentiated cancer that was considered renal cell carcinoma in combination with immunohistochemistry. (D)Case 13 showed esophageal ulcerative adenosquamous carcinoma, the tumor invaded the superficial muscle layer, and no tumor thrombus was found in the vasculature. (E) The specimen of case 14 showed gastric adenocarcinoma with infiltrating type of low adhesion. (F)The immunohistochemistry of case 15 demonstrated cholangiocarcinoma. 


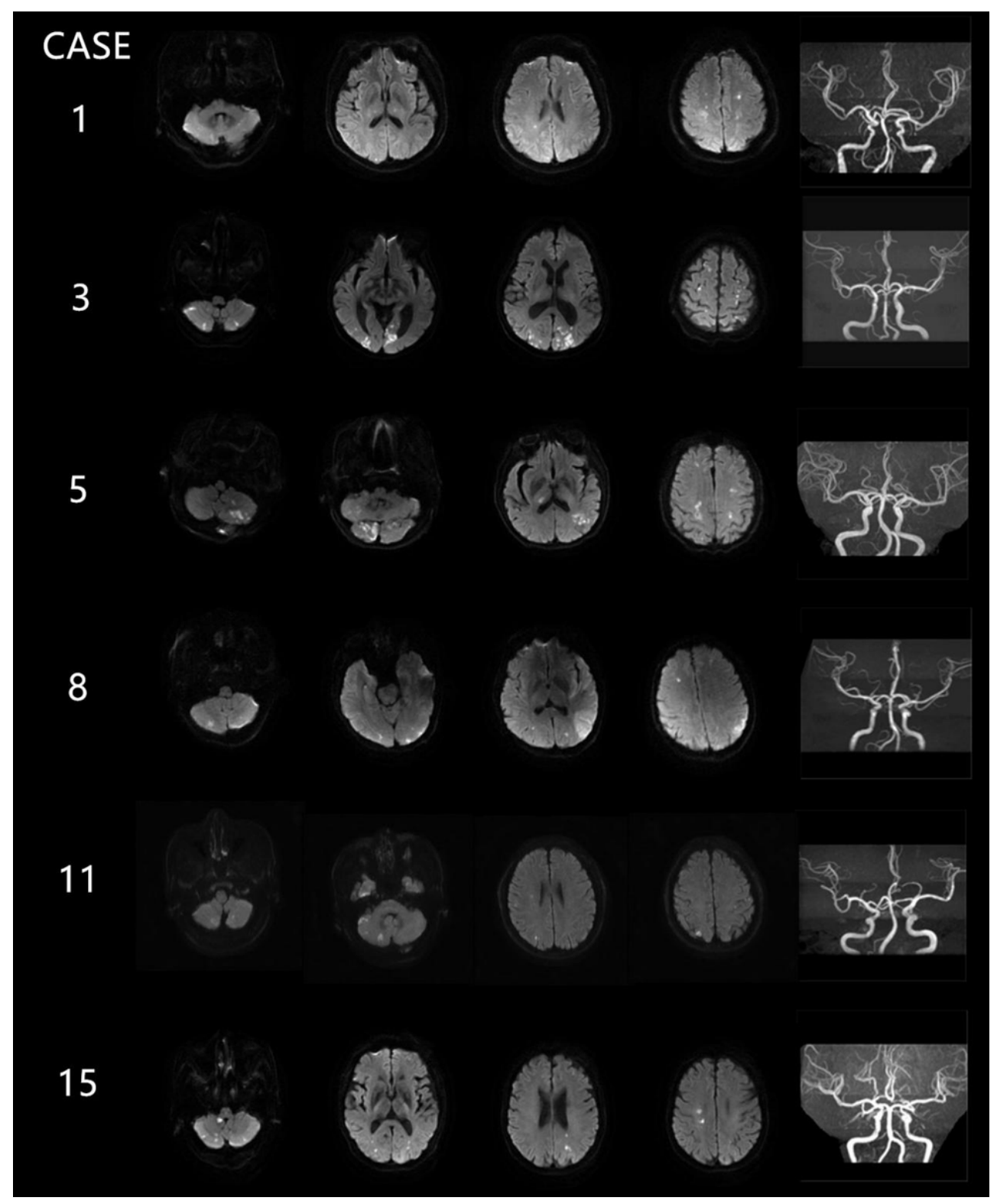

\section{Figure 2}

Multiple acute ischemic lesions located in different vascular territories. On DWI images, these lesions show restricted diffusion. There was no significant stenosis of the brain arteries on MRA. 